\title{
Knowledge, attitude and preventive practices related to COVID-19: a cross-sectional study in two Pakistani university populations
}

\author{
Muhammad Salman ${ }^{1}$ ( $\cdot$ Zia UI Mustafa ${ }^{2} \cdot$ Noman Asif $^{3,4} \cdot$ Haider Abbas Zaidi $^{4} \cdot$ Khalid Hussain $^{3}$. \\ Naureen Shehzadi ${ }^{3} \cdot$ Tahir Mehmood Khan $^{5} \cdot$ Zikria Saleem $^{1}$
}

Published online: 9 May 2020

(c) Springer Nature Switzerland AG 2020

\begin{abstract}
Objective The aim of this study was to assess COVID-19-related knowledge, attitudes, and preventive practices of two Pakistani university populations.

Methods A cross-sectional study was conducted among students and employees of two higher education institutions in Lahore, Pakistan, namely the University of Lahore and the Gulab Devi Educational Complex. Participants were recruited using a convenient sampling method. A validated 45-item, self-administered questionnaire was used to collect data. Total possible scores were $0-14$ for knowledge (scores $<7,7-10$ and $>10$ were considered to indicate poor, moderate and good knowledge, respectively); 0-7 for attitude (scores $>5$ were considered to indicate a good attitude); and 0-18 for COVID-19 preventative practices (scores $>12$ were considered to indicate good preventative practices).

Results Of the 417 enrolled participants, 416 reported that they were aware of COVID-19 and social media was the major source of their information. Mean scores were $10.12 \pm 2.20$ for knowledge (good, moderate and poor knowledge in 50.2\%, $42.8 \%$ and $7.0 \%$ of participants, respectively); $5.74 \pm 1.28$ for attitude $(65.4 \%$ of individuals had a positive attitude); and $11.04 \pm 3.34$ for COVID-19 preventative practices (only $36.5 \%$ of participants had good preventive practices).

Conclusion Pakistani university students and employees have good knowledge and attitudes regarding COVID-19, but unsatisfactory preventive practices. Therefore, health regulators should use multiple communication approaches, such as electronic, print and social media, phone messages, etc., to increase awareness and improve practices related to COVID-19.
\end{abstract}

\section{Introduction}

Coronaviruses are large, enveloped, RNA viruses, categorised into four genera; alpha, beta, delta and gamma [1]. Previously, six types of coronaviruses were pathogenic to humans, of which four species, namely 229E, OC43, NL63 and HKU1, usually caused common cold-like symptoms,

Muhammad Salman

msk5012@gmail.com;

muhammad.salman@pharm.uol.edu.pk

1 Department of Pharmacy Practice, Faculty of Pharmacy, The University of Lahore, 1-Km Defense Road, Lahore, Pakistan

2 District Headquarter Hospital, Pakpattan, Pakistan

3 Punjab University College of Pharmacy, University of the Punjab, Lahore, Pakistan

4 Gulab Devi Educational Complex, Lahore, Pakistan

5 Institute of Pharmaceutical Science, University of Veterinary and Animal Sciences, Lahore, Pakistan whereas the other two species caused severe respiratory infection, including severe acute respiratory syndrome (SARS) and Middle East respiratory syndrome (MERS). In late December 2019, an outbreak of novel coronavirus, initially called 2019-nCoV but later named SARS-CoV2, appeared in Wuhan, China [2, 3]. In just a few months, it swept across the world, becoming a global pandemic. The first positive coronavirus disease (COVID-19) case in Pakistan was reported on 26 February 2020. In order to effectively combat the disease, on 13 March 2020 [Order No. SO(I\&C-I) 1-2/2020], the government of the Punjab, a province of Pakistan, closed all educational institutions (schools, colleges and universities) and Deeni Madaris (religious schools). All religious congregations and ceremonies were suspended, marriage/banquet halls were ordered to close, and all public and private sport festivals were cancelled. Moreover, on 23 March 2020 [Order NO. SO(IS-11)1$1 / 2004$ ], a complete lockdown was imposed in the country. On 27 March 2020, it was estimated there were 13,328 
COVID-19 cases (10,018 active cases, 281 deaths and 3029 recoveries) across the country [4].

As there is no vaccine or approved cure for COVID-19, it is of immense importance that the public have good knowledge about the individual measures (physical distancing, proper hand hygiene, use of a face mask and respiratory etiquette) that will serve as the first line of defense against this disease. Therefore, the present study was conducted to evaluate knowledge, attitudes and preventive practices of COVID-19 among Pakistani university students and employees. It was conducted before the universities were closed and an aggressive media campaign was launched by the government to disseminate information related to COVID-19. Therefore, our findings may provide baseline information on awareness of the disease among educated Pakistanis, and highlight misperceptions, myths and malpractices related to it. Our findings are likely to assist the authorities in better planning of awareness campaigns to eradicate misconceptions and malpractices related to COVID-19, which may result in curtailing the disease.

\section{Methods}

\section{Study design, participants and settings}

This cross-sectional survey was carried out among students and employees at two higher educational institutions in Lahore, Pakistan, namely the University of Lahore and the Gulab Devi Educational Complex. A convenient sampling method was used to recruit the study participants (undergraduate and postgraduate students and employees). Researchers approached individuals at the study settings, from 22 February to 12 March 2020, and explained the objectives of the study. Those who consented were given the study survey.

\section{Ethical considerations}

The study protocol was approved by the Research Ethics Committee of the Department of Pharmacy Practice, Faculty of Pharmacy, the University of Lahore (REC/DPP/FOP/12). Verbal consent was obtained from each participant prior to their enrollment. Moreover, all current COVID-19 preventative measures were used during data collection.

\section{Sample size}

The sample size for the study was calculated using the Raosoft sample size calculator by keeping a margin of error of 5\%, a $95 \%$ confidence interval, a population size of 20,000 , and a $50 \%$ response distribution [5]. A minimum of 377 individuals were required for the study.

\section{Study instrument}

A self-administered questionnaire was designed based on the published literature [6-11]. The questionnaire was in English, which is the primary language of higher education in Pakistan; there was no need for an Urdu version of the questionnaire in this study. The initial draft of the questionnaire was reviewed by an expert panel (one professor, one associate professor, two assistant professors and a lecturer) for validation. The questions were revised based on the comments and suggestions of the expert panel. The final questionnaire had the following five sections:

- Section I: Seven questions regarding the demographic details of the study participants.

- Section II: Sixteen questions to explore participants' knowledge of COVID-19. The first two questions were "Have you heard of the recent corona disease outbreak?" and "If yes, where did you first learn about corona?" Those who responded 'yes' to the first question were asked to respond to the subsequent 14 COVID-19 knowledge questions. Each correct answer received 1 point, with a total possible knowledge score of $0-14$; participants with a score $<7,7-10$ and $>10$ were considered to have poor, moderate and good knowledge, respectively.

- Section III: Nine questions to assess participants' perception of COVID-19.

- Section IV: Seven questions to evaluate the attitude of study participants toward COVID-19. Each positive attitude received 1 point, with a total possible attitude score of $0-7$; participants with a score $>5$ were considered to have a good attitude.

- Section V: Six questions to evaluate the participants' preventive practices regarding COVID-19. A 4-point Likert scale ( 0 indicating 'never' and 3 indicating 'always') was used for each question. The total possible preventive practices-related score was $0-18$; participants with a score $>12$ were considered to have good preventative practices.

The questionnaire was pretested in 10 pharmacy students at the University of Lahore before it was used by the study participants. All pretest participants reported that they completely understood the questions and response options, and all questions were relevant to COVID-19.

\section{Statistical analysis}

Data were analysed using SPSS version 22 for Windows. Number and percentages were presented for categorical 
variables, and mean \pm standard deviation $(\mathrm{SD})$ were presented for continuous variables. The independent $t$ test and analysis of variance were used to determine significance, where applicable, and a $p$ value $<0.05$ was considered to indicate statistical significance.

\section{Results}

A total of 492 individuals were approached, with 417 giving consent and being enrolled in the study (response rate $84.8 \%$ ). The mean age was $22.60 \pm 4.64$ years. The demographics of the study sample are shown in Table 1 . The majority were female $(58.9 \%)$ and undergraduates $(85.3 \%)$. Of 417 participants, 416 were aware of COVID-19; the major source of their information was social media (62.0\%).

Responses of the 416 study participants regarding COVID-19 knowledge are shown in Table 2. A wide majority of the study participants knew COVID-19 was caused by a virus, but only $58.9 \%$ knew it was not a waterborne disease and $44.7 \%$ did not know the incubation period of COVID-19. Moreover, 54.1\% reported that there were approved cures for COVID-19; of these participants, the majority stated that antibiotics could cure COVID19. Moreover, $33.4 \%$ did not know that no vaccine was available for COVID-19. The mean knowledge score was $10.12 \pm 2.20$, with $50.2 \%, 42.8 \%$ and $7.0 \%$ of participants having good, moderate and poor COVID-19 knowledge, respectively. As shown in Table 3, there was no significant difference $(p>0.05)$ between knowledge scores across all demographic variables except economic class. In post hoc analysis, participants in the lower economic class had significantly lower knowledge scores than those in the middle $(p<0.001)$ or upper $(p=0.002)$ economic classes.

As shown in Table 4, most (72.4\%) participants reported they were scared of COVID-19. Approximately 58\% believed the media were overestimating COVID-19, $47.8 \%$ stated that 'lack of public awareness' was the foremost reason that COVID-19 had not yet been contained, and 54\% believed that some fruits, vegetables and herbs could help in the prevention and/or treatment of COVID-19.

\section{Table 1 Characteristics of the study population}

\begin{tabular}{|c|c|c|}
\hline Characteristic & Response & $\begin{array}{l}\text { No. of } \\
\text { participants } \\
(\%)\end{array}$ \\
\hline \multirow[t]{3}{*}{ Age, years } & $\leq 20$ & $137(32.9)$ \\
\hline & $21-25$ & $234(56.1)$ \\
\hline & $>25$ & $46(11.0)$ \\
\hline \multirow[t]{2}{*}{ Sex } & Male & $172(41.2)$ \\
\hline & Female & $245(58.8)$ \\
\hline \multirow[t]{3}{*}{ Participant categories } & Undergraduate & $356(85.3)$ \\
\hline & Postgraduate & $37(8.9)$ \\
\hline & Staff & $24(5.8)$ \\
\hline \multirow[t]{3}{*}{ Type of university education } & Medical & $68(16.3)$ \\
\hline & Pharmacy & $293(70.3)$ \\
\hline & Allied health sciences & $56(13.4)$ \\
\hline \multirow[t]{2}{*}{ Nationality } & Pakistani & $412(98.8)$ \\
\hline & Foreigner & $5(1.2)$ \\
\hline \multirow[t]{3}{*}{ Economic class } & Lower & $17(4.1)$ \\
\hline & Middle & $367(88.0)$ \\
\hline & Upper & $33(7.9)$ \\
\hline \multirow[t]{2}{*}{ Place of residence } & Rural & $67(16.1)$ \\
\hline & Urban & $350(83.9)$ \\
\hline \multirow{2}{*}{$\begin{array}{l}\text { Have you heard about the ongoing corona disease (COVID-19) } \\
\text { outbreak? }\end{array}$} & Yes & $416(99.8)$ \\
\hline & No & $1(0.2)$ \\
\hline \multirow[t]{5}{*}{ Where did you first learn about COVID-19? } & Friends/family/relatives/neighbours & $32(7.7)$ \\
\hline & Social media (Facebook/Twitter/Instagram, etc.) & $258(62.0)$ \\
\hline & Television/radio & $111(26.7)$ \\
\hline & Newspapers & $6(1.4)$ \\
\hline & Others & $9(2.1)$ \\
\hline
\end{tabular}


Table 2 Response of study participants to COVID-19 knowledge questions

\begin{tabular}{|c|c|c|}
\hline \multirow[t]{2}{*}{ Question } & \multicolumn{2}{|c|}{ No. of participants (\%) } \\
\hline & Correct & Incorrect \\
\hline What is the cause of COVID-19? & $392(94.2)$ & $24(5.8)$ \\
\hline Is COVID-19 a water-borne disease (spread by water)? & $245(58.9)$ & $171(41.1)$ \\
\hline COVID-19 is transmitted by close contact with an infected person & $394(94.7)$ & $22(5.3)$ \\
\hline What is the time range between infection with COVID-19 and the onset of symptoms? & $230(55.3)$ & $186(44.7)$ \\
\hline Fever, cough, and shortness of breath are symptoms of COVID-19 & $387(93.0)$ & $29(7.0)$ \\
\hline Myalgia (muscle ache), sore throat, and diarrhoea are also possible symptoms of COVID-19 & $226(54.3)$ & $190(45.7)$ \\
\hline Patients with underlying chronic diseases are at a higher risk of infection & $299(71.9)$ & $177(28.1)$ \\
\hline Washing hands with soap and water can help in the prevention of COVID-19 transmission? & $364(87.5)$ & $52(12.5)$ \\
\hline Wearing a face mask is an effective prevention strategy for COVID-19 & $383(92.1)$ & $33(7.9)$ \\
\hline At this moment, is there a cure for COVID-19? & $191(45.9)$ & $225(54.1)$ \\
\hline At this moment, is there a vaccine active against COVID-19? & $277(66.6)$ & $139(33.4)$ \\
\hline COVID-19 can be life-threatening & $368(88.5)$ & $48(11.5)$ \\
\hline Where was the first case of COVID-19 recorded? & $315(75.7)$ & $101(24.3)$ \\
\hline Outside of China, how many countries have reported confirmed cases of COVID-19? & $235(60.8)$ & $181(39.2)$ \\
\hline
\end{tabular}

Table 3 Between-demographic differences in knowledge, attitudes and practices scores

\begin{tabular}{|c|c|c|c|c|}
\hline \multirow[t]{2}{*}{ Variable } & \multirow[t]{2}{*}{ Subgroup } & \multicolumn{3}{|c|}{ Mean score \pm SD } \\
\hline & & Knowledge & Attitudes & Practices \\
\hline \multirow[t]{4}{*}{ Age, years } & $\leq 20$ & $10.02 \pm 2.09$ & $5.80 \pm 1.27$ & $11.12 \pm 3.46$ \\
\hline & $21-25$ & $10.23 \pm 2.22$ & $5.76 \pm 1.30$ & $10.87 \pm 3.35$ \\
\hline & $>25$ & $10.34 \pm 2.37$ & $2.48 \pm 1.19$ & $11.57 \pm 2.92$ \\
\hline & $p$ value & 0.594 & 0.858 & 0.276 \\
\hline \multirow[t]{3}{*}{ Sex } & Male & $9.92 \pm 2.37$ & $5.43 \pm 1.43$ & $10.54 \pm 3.50$ \\
\hline & Female & $10.13 \pm 2.10$ & $5.96 \pm 1.12$ & $11.38 \pm 3.19$ \\
\hline & $p$ value & 0.336 & $<0.001$ & 0.012 \\
\hline \multirow[t]{4}{*}{ Participant categories } & Undergraduate & $10.21 \pm 2.13$ & $5.76 \pm 1.29$ & $10.99 \pm 3.36$ \\
\hline & Postgraduate & $9.72 \pm 2.61$ & $5.84 \pm 1.24$ & $11.54 \pm 3.56$ \\
\hline & Staff & $10.33 \pm 2.46$ & $5.25 \pm 1.03$ & $10.83 \pm 2.65$ \\
\hline & $p$ value & 0.416 & 0.614 & 0.378 \\
\hline \multirow[t]{4}{*}{ Type of university education } & Medical & $10.26 \pm 2.10$ & $5.79 \pm 1.29$ & $10.96 \pm 3.34$ \\
\hline & Pharmacy & $10.18 \pm 2.19$ & $5.79 \pm 1.24$ & $11.31 \pm 3.53$ \\
\hline & Allied health sciences & $10.05 \pm 2.31$ & $5.43 \pm 1.22$ & $11.12 \pm 3.15$ \\
\hline & $p$ value & 0.867 & 0.729 & 0.934 \\
\hline \multirow[t]{4}{*}{ Economic class } & Lower & $7.94 \pm 3.36$ & $5.47 \pm 1.59$ & $8.59 \pm 4.18$ \\
\hline & Middle & $10.26 \pm 2.08$ & $5.75 \pm 1.26$ & $10.94 \pm 3.19$ \\
\hline & Upper & $10.45 \pm 2.12$ & $5.82 \pm 1.29$ & $13.39 \pm 3.31$ \\
\hline & $p$ value & $<0.001$ & 0.643 & $<0.001$ \\
\hline \multirow[t]{3}{*}{ Place of residence } & Rural & $9.84 \pm 2.23$ & $5.09 \pm 1.59$ & $10.67 \pm 4.11$ \\
\hline & Urban & $10.08 \pm 2.21$ & $5.87 \pm 1.17$ & $11,011 \pm 3.17$ \\
\hline & $p$ value & 0.403 & $<0.001$ & 0.311 \\
\hline
\end{tabular}

$S D$ standard deviation 
Table 4 Response of study participants to COVID-19 perception questions

\begin{tabular}{|c|c|c|}
\hline Question & Response & $\begin{array}{l}\text { No. of par- } \\
\text { ticipants } \\
(\%)\end{array}$ \\
\hline \multirow[t]{2}{*}{ Are you afraid of COVID-19? } & Yes & $301(72.4)$ \\
\hline & No & $115(27.6)$ \\
\hline \multirow[t]{4}{*}{ If yes, why are you afraid of COVID-19? } & No cure & $95(31.6)$ \\
\hline & Is highly contagious & $112(37.2)$ \\
\hline & Is a new disease & $38(12.6)$ \\
\hline & No preventive methods & $56(18.6)$ \\
\hline \multirow[t]{3}{*}{ Do you believe the media is overestimating COVID-19? } & Yes & $241(57.9)$ \\
\hline & No & $171(41.1)$ \\
\hline & Unanswered & $4(1.0)$ \\
\hline \multirow[t]{4}{*}{ Why has it been difficult to stop the spread of COVID-19? } & Lack of awareness & $199(47.8)$ \\
\hline & Inadequate health personnel & $110(26.4)$ \\
\hline & Porous borders & $58(13.9)$ \\
\hline & Other & $49(11.8)$ \\
\hline \multirow[t]{3}{*}{ Do you think COVID-19 can be brought under control in $2020 ?$} & Yes & $312(75.0)$ \\
\hline & No & $95(22.8)$ \\
\hline & Unanswered & $9(2.5)$ \\
\hline \multirow[t]{3}{*}{ Do you think that people suspected to have COVID-19 should be quarantined? } & Yes & $323(77.6)$ \\
\hline & No & $84(20.2)$ \\
\hline & Unanswered & $9(2.2)$ \\
\hline \multirow[t]{3}{*}{ Do you believe there are some foods that can effectively cure or prevent COVID-19? } & Yes & $225(54.1)$ \\
\hline & No & $188(45.2)$ \\
\hline & Unanswered & $3(0.7)$ \\
\hline \multirow{3}{*}{$\begin{array}{l}\text { Do you think thermal surveillance/screening of passengers at air or sea ports can prevent the } \\
\text { spread of COVID-19? }\end{array}$} & Yes & $337(81.0)$ \\
\hline & No & $76(18.3)$ \\
\hline & Unanswered & $3(0.7)$ \\
\hline \multirow[t]{3}{*}{ Do you think it is safe to visit a country with reported COVID-19? } & Yes & $58(13.9)$ \\
\hline & No & $350(84.1)$ \\
\hline & Unanswered & $8(0.9)$ \\
\hline
\end{tabular}

\section{Table 5 Response of study participants to COVID-19 attitude questions}

\begin{tabular}{|lcr|}
\hline Question & No. of participants (\%) & Positive \\
\cline { 2 - 3 } & Negative & $332(79.8)$ \\
\hline COVID-19 is not a serious disease & $84(20.2)$ & $353(84.9)$ \\
\hline Can it be treated at home without staying in touch with a doctor? & $63(15.1)$ & $318(76.4)$ \\
\hline If a corona vaccine is available, would you have it? & $25(6.0)$ & $391(94.0)$ \\
\hline Is it important to use a face mask as a prevention strategy? & $44(10.6)$ & $372(89.4)$ \\
\hline Is it important to follow cough or sneezing etiquette? & $96(23.1)$ & $320(76.9)$ \\
\hline Health education has nothing to do with disease prevention & $118(28.4)$ & $298(71.6)$
\end{tabular}

The attitude of study participants towards COVID19 are shown in Table 5. The mean attitude score was $5.74 \pm 1.28$, with $65.4 \%$ of participants having a positive attitude. Attitude scores did not significantly differ between age, economic class, education and participant categories (Table 3), however attitude scores were better in females than in males $(5.43 \pm 1.43$ vs. $5.96 \pm 1.12 ; p<0.001)$ and 
Table 6 Response of study participants to COVID-19 preventative practice questions

\begin{tabular}{|c|c|c|c|c|}
\hline \multirow[t]{2}{*}{ Question } & \multicolumn{4}{|c|}{ No. of participants (\%) } \\
\hline & Never & Rarely & Sometimes & Always \\
\hline I cover my nose and mouth with a tissue during sneezing or coughing & $28(6.7)$ & $65(15.6)$ & $151(36.3)$ & $172(41.3)$ \\
\hline I throw the used tissue in the trash bin & $19(4.6)$ & $55(13.2)$ & $101(24.3)$ & $241(57.9)$ \\
\hline If no tissue is available, I cough or sneeze into my upper sleeve & $109(26.2)$ & $90(21.6)$ & $136(32.7)$ & $81(19.5)$ \\
\hline I avoid touching my face (eyes, nose or mouth) with contaminated hands & $49(11.8)$ & $85(20.4)$ & $121(29.1)$ & $161(38.7)$ \\
\hline $\begin{array}{l}\text { I use soap and water to wash my hands quickly after coughing or sneezing or } \\
\text { touching contaminated objects such as a tissue }\end{array}$ & $44(10.6)$ & $100(10.6)$ & $127(30.5)$ & $145(34.9)$ \\
\hline I use a face mask in the crowds and when I visit healthcare settings nowadays & $148(35.6)$ & $88(21.2)$ & $104(25.0)$ & $76(18.3)$ \\
\hline
\end{tabular}

in individuals from urban areas than in those from rural areas $(5.09 \pm 1.59$ vs. $5.87 \pm 1.17 ; p<0.001)$.

Participants' preventive practices related to COVID-19 are shown in Table 6 . The mean preventive practice score was $11.04 \pm 3.34$, with $36.5 \%$ of participants having good preventive practices related to COVID-19. Preventative practices were better in females than in males $(p=0.012)$ and in participants in the middle $(p=0.004)$ and upper $(p<0.001)$ economic categories than in those in the lower economic category (Table 3 ).

\section{Discussion}

To our knowledge, this is the first study that investigated COVID-19-associated knowledge, attitudes and practices among Pakistani university students and staff. COVID-19 is neither an air-borne nor water-borne disease; it spreads from infected individuals to others through respiratory droplets while sneezing or coughing, and through contaminated hands. The incubation period has been reported to be 5.2 days (95\% CI 4-7) [12], however the Centers for Disease Control and Prevention (CDC) suggests it can range from 2 to 14 days [13]. The most common symptoms of COVID-19 are fever, fatigue, and dry cough, with one-third of patients experiencing dyspnoea [7, 8]. Other symptoms include myalgia, headache, sore throat, and diarrhoea [8]. Moreover, the elderly, patients with chronic diseases (hypertension, diabetes, cardiovascular, cerebrovascular disease and chronic respiratory diseases) and healthcare professionals are at greater risk of COVID-19 [8, 14]. In our study, most participants knew the mode of transmission of COVID-19, $55.3 \%$ were aware of its incubation period, $93.7 \%$ knew the common symptoms, and $72 \%$ were aware of high-risk individuals. To date, management of COVID-19 has been largely supportive. Several drugs approved for other indications (e.g. chloroquine, hydroxychloroquine, lopinavir, ritonavir, sofosbovir, ribavirin, etc.) and some investigational drugs (e.g. remdesivir, favipiravir) are being investigated to prevent or treat COVID-19 [15]. Surprisingly, $\approx 33 \%$ and
$54 \%$ of study participants were unaware that there was no vaccine and any approved cure for COVID-19, respectively. Overall, it was encouraging to see that the majority of university students and employees had good COVID-19 knowledge and attitudes. This might be because our sample comprised staff and students belonging to the medical, pharmacy and allied health sciences fields of education. Similar studies conducted in China, Jordan and Saudi Arabia reported better knowledge, attitudes and practices regarding COVID-19 in university students [16-18] than were reported in our study in Pakistan.

In our study, despite the overall good knowledge and attitudes, it was worrisome that preventive practices related to COVID-19 were far from satisfactory. If the educated sector of Pakistan has poor preventive practices, one may wonder what the practices of the general public will be. We believe that due to limited access to online health information resources, vulnerable populations such as illiterate or lowliterate, geriatric and rural populations would be more likely to have poor knowledge, attitudes, and preventive practices.

Our study has some limitations. The study was conducted among university students and employees belonging to medical, pharmacy and allied health science departments. Moreover, we used a non-probability sampling method, namely the convenient sampling method. Therefore, our findings may not be representative of the entire Pakistani university population. Awareness of a particular disease can be influenced by the gravity of the situation. Since COVID19 has been declared a pandemic and aggressive awareness campaigns are in full swing, the knowledge, attitudes and practices are likely to be improving by the day.

\section{Conclusions}

Pakistani university students and employees have satisfactory knowledge and attitudes to COVID-19, however their preventive practices related to the disease are inadequate. Therefore, there is dire need of campaigns to improve preventive practices such as physical distancing, handwashing 
and respiratory etiquette. Health regulators can use multiple communication tools (e.g. social media platforms, TV, radio, phone texts, etc.) to educate and enforce these prevention practices.

\section{Take home messages}

- Be aware that the COVID-19 pandemic is the most devastating health crisis since the influenza pandemic in 1918, and that no vaccine or approved treatment is currently available.

- Realise that awareness campaigns can help ensure that appropriate knowledge about measures that can serve as the first line of defense against COVID-19 (e.g. physical distancing, proper hand hygiene, use of a face mask and respiratory etiquette) are available to the public.

- Recognise that due to limited access to online health information resources, vulnerable individuals (e.g. illiterate, low-literate, geriatric and rural populations) are more likely to have poor knowledge, attitudes, and preventive practices.

Acknowledgements The authors are grateful to Ms. Maham Waqar, Ms. Ayesha, Ms. Mahnoor Shahid, Ms. Maryam Ashraf, Ms. Iffrah Shah, Ms. Sonia Sarwar and Ms. Hafiza Warda for assisting in the data collection, and are also thankful to the study participants for sparing their valuable time to complete the questionnaires.

Author contributions MS and KH conceived and designed the study; MS and ZUM conducted the literature review; MS, NA, HAZ and ZS collected the data; MS, NS and ZUM analysed and interpreted data; MS drafted the manuscript; and TMK critically revised the manuscript. All authors approved the manuscript submitted for publication.

\section{Compliance with ethical standards}

Conflict of interest None declared.

Funding The authors did not receive any funding for this study.

\section{References}

1. de Wilde AH, Snijder EJ, Kikkert M, et al. Host factors in coronavirus replication. Curr Top Microbiol Immunol. 2018;419:1-42.

2. World Health Organization. Coronavirus. https://www.who.int/ health-topics/coronavirus\#tab=tab_1. Accessed 18 Mar 2020.
3. Zhou P, Yang XL, Wang XG, et al. A pneumonia outbreak associated with a new coronavirus of probable bat origin. Nature. 2020;579:270-3.

4. National Institute of Health, Islamic Republic of Pakistan. COVID-19 updates. https://covid.gov.pk/stats/pakistan. Accessed 27 Mar 2020.

5. Raosoft. Sample size calculator. https://www.raosoft.com/sampl esize.html. Accessed 18 Feb 2020.

6. Del Rio C, Malani PN. Novel coronavirus-important information for clinicians. JAMA. 2019;2020(323):1039-40.

7. Chen N, Zhou M, Dong X, et al. Epidemiological and clinical characteristics of 99 cases of 2019 novel coronavirus pneumonia in Wuhan, China: a descriptive study. Lancet. 2020;395:507-13.

8. Wang D, Hu B, Hu C, et al. Clinical characteristics of 138 hospitalized patients with 2019 novel coronavirus-infected pneumonia in Wuhan, China. JAMA. 2020;323:1061-9.

9. Asaad AM, El-Sokkary RH, Alzamanan MA, et al. Knowledge and attitudes towards Middle East respiratory syndrome-coronavirus (MERS-CoV) among health care workers in south-western Saudi Arabia. East Mediterr Health J. 2020;26(4):435-42.

10. Nour MO, Babilghith AO, Natto HA, et al. Knowledge, attitude and practices of healthcare providers towards MERS-CoV infection at Makkah hospitals, KSA. Int Res J Med Med Sci. 2015;3:103-12.

11. Salman M, Shehzadi N, Hussain K, et al. Knowledge of Ebola virus disease among a university population: a cross-sectional study. Am J Infect Control. 2017;45:e23-e2525.

12. Li Q, Guan X, Wu P, et al. Early transmission dynamics in Wuhan, China, of novel coronavirus-infected pneumonia. N Engl J Med. 2020;382(13):1199-207.

13. Center for Disease Control and Prevention. Symptoms of coronavirus. https://www.cdc.gov/coronavirus/2019-ncov/symptomstesting/symptoms.html. Accessed 18 Mar 2020.

14. Wu Z, McGoogan JM. Characteristics of and important lessons from the Coronavirus Disease 2019 (COVID-19) outbreak in China: summary of a report of 72,314 cases from the Chinese Center for Disease Control and Prevention. JAMA. 2020. https:// doi.org/10.1001/jama.2020.2648.

15. Sanders JM, Monogue ML, Jodlowski TZ, et al. Pharmacologic treatments for coronavirus disease 2019 (COVID-19): a review. JAMA. Epub 13 Feb 2020. doi:10.1001/jama.2020.6019

16. Peng Y, Pei C, Zheng Y, et al. Knowledge, attitude and practice associated with COVID-19 among university students: a crosssectional survey in China. https://assets.researchsquare.com/files /rs-21185/v1/Manuscript.pdf. Accessed 25 Apr 2020.

17. Alzoubi H, Alnawaiseh N, Asma'a Al-Mnayyis MA, et al. COVID-19-knowledge, attitude and practice among medical and non-medical University Students in Jordan. J Pure Appl Microbiol. 2020;14:17-24.

18. White MS, Omer M, Mohammad GN. Knowledge, attitude and practice on prevention of airborne and droplet infections during the outbreak of corona virus among the College Students in University of Bisha, Saudi Arabia. Int J Contemp Res Rev. 2020;11:20773-6. 